\title{
Accidental Methadone Poisoning in a Four-Year-Old Child Reversed With Continuous Intravenous Infusion of Naloxone
}

\author{
Balamurugan Supparamaniam ${ }^{\mathrm{a}, \mathrm{c}}$, Rahmah Yunus ${ }^{\mathrm{b}}$, Jing Ying Fong ${ }^{\mathrm{a}}$, Kai Lun Tang ${ }^{\mathrm{a}}$
}

\begin{abstract}
Reported case of methadone poisoning among children is infrequent in Malaysia. Since the implementation of methadone maintenance therapy (MMT) programme by Malaysian Ministry of Health in year 2006, there are only three case reports of methadone poisoning in children. Methadone toxicity in children can be deadly if antidote and supportive measures are not instituted in time. We report a case of accidental ingestion of about $25 \mathrm{mg}$ of methadone in a 4-year-old boy. The methadone syrup belonged to his father, a former intravenous drug user (IVDU), who is currently a participant of the MMT detoxification programme under the supervision of a licensed general practitioner. The child presented with typical early signs and symptoms opioid toxicity. Upon examination, vital signs were normal, but he appeared lethargic and drowsy. Venous blood gas results noted mild respiratory acidosis and complete blood count revealed leukocytosis. He was treated with continuous intravenous infusion (CIVI) naloxone $10 \mu \mathrm{g} / \mathrm{kg} / \mathrm{h}$ for approximately $78 \mathrm{~h}$. He was hospitalized for 6 days and discharged well. Advice should be given to family who has patient under MMT programme with take-home doses to be more cautious in storage of methadone syrup at home, and to keep the bottle far from the reach of children. Methadone poisoning in children can be deadly and early administration of naloxone as CIVI can effectively reverse its toxicity.
\end{abstract}

Keywords: Methadone poisoning; Naloxone; Pediatric; Drug toxicity

\section{Introduction}

Methadone is a synthetic opioid compound used in treatment

Manuscript submitted June 13, 2020, accepted July 2, 2020

Published online March 19, 2021

aPharmacy Department, Seberang Jaya Hospital (Penang), Ministry of Health, Malaysia

bPediatric Department, Seberang Jaya Hospital (Penang), Ministry of Health, Malaysia

${ }^{\mathrm{c} C o r r e s p o n d i n g ~ A u t h o r: ~ B a l a m u r u g a n ~ S u p p a r a m a n i a m, ~ P h a r m a c y ~ D e p a r t-~}$ ment, Seberang Jaya Hospital, Jalan Tun Hussein Onn, 13700 Perai, Pulau Pinang, Malaysia. Email: bala5661@gmail.com

doi: https://doi.org/10.14740/ijcp386 of opioid dependence patients particularly heroin. Methadone has been legalized for treatment of opioid dependence and opioid withdrawal since 1970's globally [1]. Methadone is available in both oral tablet and syrup form. It is known to be an opioid with very long half-life. Malaysia introduced methadone program in October 2005 [2]. In Malaysia, methadone syrup is available in selected government health settings (hospitals and clinics), as well as private general practitioners' (GP's) clinics. In government health settings, methadone is dispensed as directly observed therapy (DOT) by pharmacists. On the other hand, in selected private GP's clinic, DOTs methadone is supervised by medical practitioners. Occasionally, several take-away doses are allowed for patient's home consumption.

Methadone maintenance therapy (MMT) programme was proven to be effective in reducing drug use, risk of getting human immunodeficiency virus (HIV) and other blood-borne viruses' infection, crime and imprisonment [2]. However, initiation of MMT programme poses certain risks and disadvantages, i.e., abuse of methadone by drug addicts, presence of methadone at home puts children at risk of accidental ingestion [3]. Methadone poisoning cases involving children is rarely reported in Malaysia. Methadone toxicity in children can be deadly if antidote and supportive measures are not instituted in time [4]. We are reporting a case of accidental methadone ingestion and toxicity in 4-year-old child reversed by prolonged continuous intravenous infusion (CIVI) of naloxone. It is aimed to raise awareness among general public and healthcare professionals caring for pediatric population.

\section{Case Report}

A 4-year-old boy, weighing $15 \mathrm{~kg}$, presented to the emergency department with excessive drowsiness and lethargy. History of present illness revealed that it was probably a case of accidental ingestion of methadone syrup at home. Patient's father was a former intravenous drug user (IVDU) and currently on MMT. He often brought back syrup methadone as "take-away dose" in an undiluted form from licensed private GP. According to the patient's mother, his son was playing with cousin brother in her room when he noticed the bottle of methadone syrup and drank it. She confirmed about the ingestion after she found that patient was holding an empty methadone bottle in hand. She did not attempt to induce vomiting and not sure what 
Table 1. Laboratory Parameters Monitored in Ward

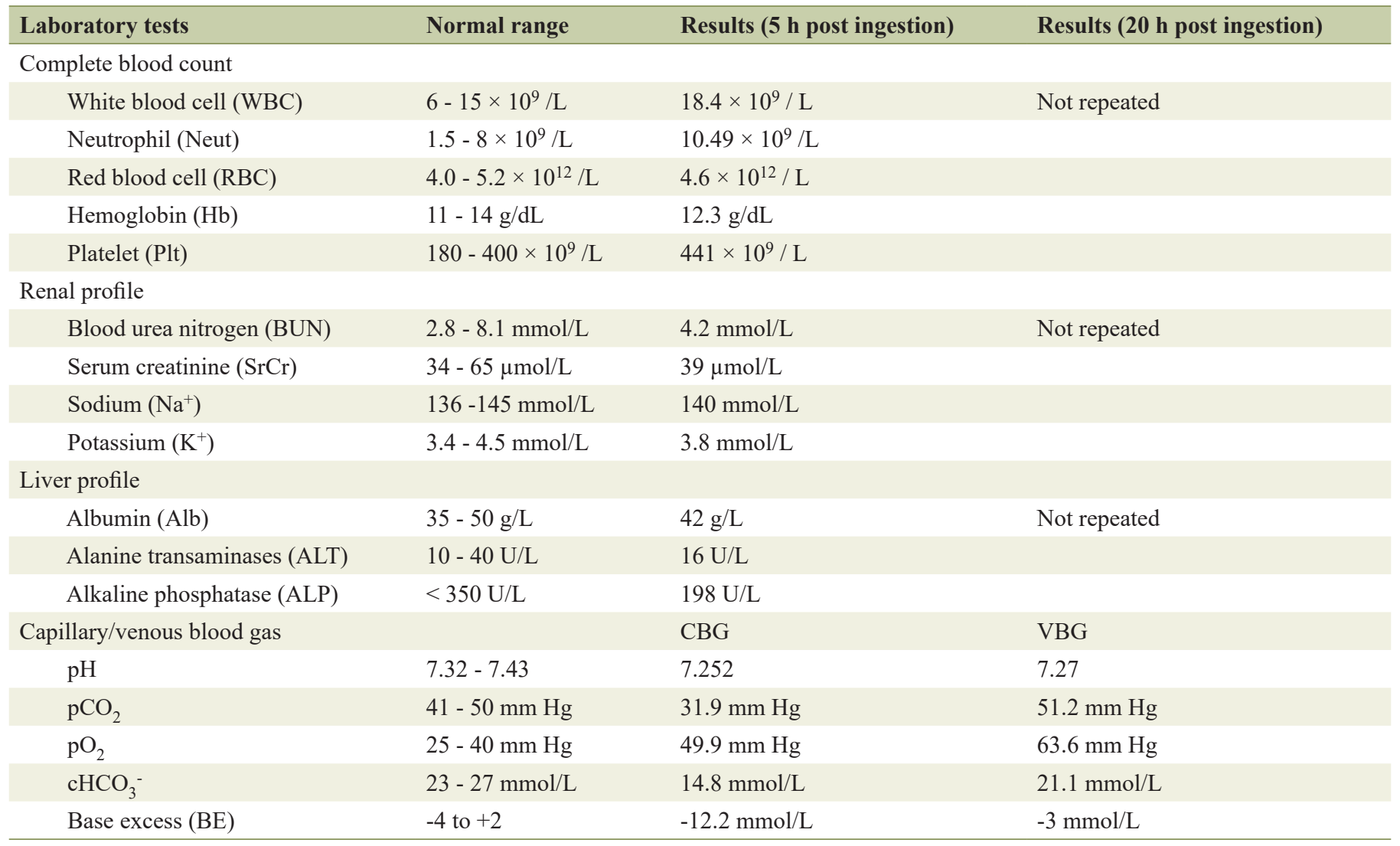

CBG: capillary blood gases; VBG: venous blood gases.

to do. Patient did not vomit after the ingestion of methadone syrup. After $1.5 \mathrm{~h}$, she noticed that the child became increasingly drowsy. She tried to feed the child some milk but the child refused. Hence, she immediately brought him to hospital. Upon further inquiry, father estimated that the child had probably ingested all $5 \mathrm{~mL}$ of methadone syrup that was left in the bottle. The standard concentration of methadone syrup available in Malaysia is $5 \mathrm{mg} / \mathrm{mL}$. Hence, we estimated that the child had ingested $25 \mathrm{mg}$ of methadone, which is about $1.7 \mathrm{mg} / \mathrm{kg}$.

Patient's past developmental milestones were up to age. He had no known underlying chronic medical illnesses, not on any chronic medications or any over-the-counter medications prior to diagnosis, and immunization was up to age. Patient is the only child in the family and he stays with the mother at home. They stayed in an apartment unit of a high-density residential apartment block. He was taken care of by his aunt during the day and back to be with his mother in the evening. We were not sure if the mother is doing any odd jobs during the day. According to her, the child's father was currently working as a shipment operator at the port; she herself is a housewife and single mother. They have been separated but her husband was still keeping his personal belongings at home. The child's father returned home occasionally and stayed for a few days when he was off duty. When he returned home, he usually brought back with him the take-away doses of syrup methadone and kept the bottle in the room.
On admission, patient's vital signs were normal, i.e., blood pressure (BP) $93 / 51 \mathrm{~mm} \mathrm{Hg}$, pulse oximetry $\left(\mathrm{SPO}_{2}\right) 100 \%$, pulse rate (PR) 111 beats/min, respiratory rate (RR) 20 breaths/ min, and temperature $36.5^{\circ} \mathrm{C}$. Physical examination revealed that patient appeared lethargic, drowsy but still able to open eye spontaneously, pupils $(2 \mathrm{~mm} / 2 \mathrm{~mm})$ are equal and reactive. Breathing effort was good and regular; there were no signs of respiratory depression. Muscles tone was normal, however full neurological examination for power and detail reflexes were unable to be performed due to the child being very fretful and not cooperative. Patient vomited twice since admission. Besides, he was able to move all four limbs, pulse volume good and capillary refill time $(\mathrm{CRT})<2$ s. General screening for non-accidental injury (NAI) did not find any external injuries or abuse marks. Methadone serum/plasma concentration assay was not readily available. Laboratory parameters (Table 1) were all normal except for capillary/venous blood gas and leukocytes count.

In the emergency department, patient was put on facemask oxygen $\left(\mathrm{FMO}_{2}\right) 5 \mathrm{~L} / \mathrm{min}$ and admitted to pediatric ward for close observation. In the pediatric ward, the child was kept nil by mouth and maintained on full hydration using intravenous (IV) dextrose saline drip. Initial blood gases result from the capillary was suggestive of metabolic acidosis. In view of the excessive drowsiness which requires close monitoring of vital signs in ward, patient was given a test dose of IV naloxone 
Table 2. Details of Patient's Clinical Manifestations Before and After Given Intravenous (IV) Naloxone

\begin{tabular}{lll}
\hline Vital signs and clinical parameters & Before naloxone & After naloxone \\
\hline General condition & Sleepy, drowsy, needed pain stimuli to wake child & Awake, less drowsy \\
Glasgow coma scale (GCS) & GCS not done (child sleeping) & GCS full \\
Bilateral pupils & $2 \mathrm{~mm} / 2 \mathrm{~mm}$ (equal and reactive) & $3 \mathrm{~mm} / 3 \mathrm{~mm}($ equal and reactive) \\
Oxygen saturation $\left(\mathrm{SPO}_{2}\right)$ & $100 \%$ under RA & $100 \%$ under RA \\
Breathing pattern & Regular breathing & Regular breathing \\
Behavior & Behavioral changes (restless, crying) & Back to normal self \\
Central nervous system & Tone normal, power 5/5 & Tone normal, power 5/5 \\
\hline
\end{tabular}

RA: room air.

(10 $\mu \mathrm{g} / \mathrm{kg} / \mathrm{dose})$. The decision to initiate treatment using intermittent dose of IV naloxone was based exclusively on clinical manifestations without serum/plasma methadone concentration. He was continued with $5 \mathrm{~L} / \mathrm{min}$ of oxygen support via facemask in view of subsequent venous blood gases which suggestive towards mild respiratory acidosis. Patient did not present with respiratory depression and bradycardia. After the initial dose of IV naloxone $150 \mu \mathrm{g}(10 \mu \mathrm{g} / \mathrm{kg} / \mathrm{dose})$, which was infused over $20 \mathrm{~min}$, patient became more alert and appeared less drowsy within $60 \mathrm{~min}$. Details of bedside examination were included in Table 2.

The child was alert and stable after the initial dose of naloxone. However, he started to appear having on and off drowsiness several hours later. Approximately $9 \mathrm{~h}$ after the initial dose of IV naloxone, patient was eventually started on continuous infusion of IV naloxone $10 \mu \mathrm{g} / \mathrm{kg} / \mathrm{h}(4.5 \mathrm{mg}$ in 30 $\mathrm{mL}$ normal saline (NS) infused at $1 \mathrm{~mL} / \mathrm{h}$; later adjusted to $3.8 \mathrm{mg}$ in $50 \mathrm{~mL}$ NS infused at $2 \mathrm{~mL} / \mathrm{h}$ ) and continued for 30 $\mathrm{h}$ before a gradual dose reduction was planned. IVI naloxone dose was gradually reduced from the initial $10 \mu \mathrm{g} / \mathrm{kg} / \mathrm{h}$ to 7.5 $\mu \mathrm{g} / \mathrm{kg} / \mathrm{h}$ and then $5 \mu \mathrm{g} / \mathrm{kg} / \mathrm{h}$ over the next $14 \mathrm{~h}$. At the dose of $5 \mu \mathrm{g} / \mathrm{kg} / \mathrm{h}$ of IVI naloxone, it was noted that patient developed bradycardia with heart rate dropped from 95 - 110 beats/min to around 76 - 84 beats/min and appeared increasingly drowsy. Dose of IVI naloxone was up titrated to $7.5 \mu \mathrm{g} / \mathrm{kg} / \mathrm{h}$. On the fourth day, dose of IVI naloxone was gradually reduced to 2.5 $\mu \mathrm{g} / \mathrm{kg} / \mathrm{h}$ and eventually off. Total duration of naloxone infusion was estimated at approximately $78 \mathrm{~h}$, which suggested that total duration of methadone toxicity effect lasted for $90 \mathrm{~h}$ since the ingestion. On the fifth day, patient had one episode of vomiting, otherwise patient was stable and alert. Patient was also treated with one dose of oral paracetamol for one documented high temperature in ward $\left(>38^{\circ} \mathrm{C}\right)$ and few doses of syrup lactulose $7 \mathrm{~mL} \mathrm{ON}$ to relieve his constipation since methadone ingestion. No abnormal electrocardiography (ECG) findings noted, no prolongation of P-R wave interval, and QTc interval was $0.3 \mathrm{~ms}$.

The child was hospitalized for 6 days and discharged well. Advice was given to parents to ensure safe storage of methadone syrup at home, keeping the bottle far from the reach of children and to take back methadone syrup only in the diluted form. Two months after discharge, during clinic follow-up, physical and neurological assessment was done by doctor in the pediatric clinic. It was found that patient was active as usual, with all motor functions, speech and social activity up to age. The father had changed his MMT take-home doses to DOT, and he no longer keeps syrup methadone at home. Other medications and toxic household substances have been relocated to a safer storage area to prevent from child's reach.

\section{Discussion}

Methadone poisoning cases among children is infrequent in Malaysia. Strict regulatory and dispensing policy for MMT in the government hospitals and government health clinics discouraged authorized personnel to allow "take-home doses" for MMT participants. In Malaysia, Ministry of Health has only approved the use of methadone for treatment of opioid addiction, not as part of the treatment for severe pain. Methadone dispensing and counseling are standardized and regulated based on national guideline published by the Pharmaceutical Services Division Ministry of Health Malaysia [5]. Based on the dispensing policy for "take-home dose", maximum three doses with each dose of methadone diluted with at least 50 $100 \mathrm{~mL}$ of drinking water before allowed to be brought home. Dispensing of undiluted methadone syrup as "take-home dose" is completely forbidden [5]. However, as in our case which involved the private practice division, some GPs might not comply with the MMT policy and dispensed undiluted methadone as "take-home dose" for their patients. If each dose of methadone was diluted into at least $50-100 \mathrm{~mL}$ of drinking water as per guideline recommendation, young children might not be able to finish drinking the whole bottle and hence, the dosage ingested could have been limited to a lower extent in case of acute poisoning.

Common causes of methadone poisoning in children reported worldwide was due to negligence in safe storage, mistaken as other medicines and intentional use to pacify child by parents $[6,7]$. There were also foul play cases reported where children were intentionally poisoned by parents who are drug addicts [6]. Following a thorough history of incidence taken from both parents, intentional poisoning was ruled out by clinician. Methadone toxicity in children can be deadly if antidote and supportive measures are not instituted in time [8]. Usual initial dose of methadone for moderate to severe pain relief in children ranged between $50-100 \mu \mathrm{g} / \mathrm{kg} / \mathrm{dose}$ [9-12]. In reported cases of acute methadone poisoning, dosage as low 
as $0.5-1 \mathrm{mg} / \mathrm{kg}$ have been reported to potentially cause lifethreatening toxicity (i.e., respiratory depression) in children [13-15]. As in this case, the child was suspected to have ingested $25 \mathrm{mg}$ of methadone, approximately $1.7 \mathrm{mg} / \mathrm{kg}$, which equate to almost 17 times of the usual therapeutic dose.

The most life-threatening toxicity following methadone poisoning is respiratory depression [15]. Central nervous system depression (i.e., drowsiness, reduced consciousness) and miosis were the two most commonly reported clinical signs and symptoms in children with methadone poisoning [7, 8, 1416]. The toxicity presentations in the child followed the similar pattern as other reported cases although the child did not develop severe respiratory depression or apnea episodes. Respiratory depression was preceded by increasing sleepiness and then a decreased level of consciousness without sudden onset of apnea episode [17]. Onset of toxic effects of methadone was approximately $1.5 \mathrm{~h}$ post ingestion, whereby the child became drowsy and appeared lethargic, which was found to be consistent with the mean time of onset reported in other cases $[15,18]$. According to Eizadi-Mood et al, GCS had prognostic value for the outcome of therapy in methadone intoxicated patients, and patients with higher GCS on admission had better outcome [19]. As in our case, although GCS scoring was not given in the emergency department, physical examination revealed that patient was drowsy yet still able to open eye spontaneously. Methadone is rapidly absorbed orally and its concentration in plasma and in the brain rises within $1-2 \mathrm{~h}$ [20]. This could have explained the early onset of toxicity signs and symptoms following acute poisoning of methadone. The parent's quick response by bringing the child to hospital after noticed him to have increasing drowsiness could have saved his live. Furthermore, a thorough and accurate history of incidence (including time of ingestion, initial clinical manifestation, possible substances, estimated amount, etc.) provided valuable clues for the management of this poisoning case although methadone serum/urine concentration assay was not readily available. Clinician's awareness of the potential of prolonged toxicity effects was heightened when they were informed that the bottle of red colour syrup belonged to patient's father who was a participant of MMT program. Hence, patient was put on very close monitoring (i.e., hourly for $9 \mathrm{~h}$ ) for signs and symptoms of opioid toxicity before initiation of naloxone infusion.

This patient received a total of $78 \mathrm{~h}$ of infusion naloxone to neutralize toxicity of methadone following acute poisoning. Naloxone infusion was known as treatment option for treating opioid poisoning cases with a mean infusing time of $51 \mathrm{~h}$ $[13,18]$. Methadone was known to have a wide interindividual pharmacokinetics and pharmacodynamic variability in both adults and children owing to the action of cytochrome P450 enzyme genetic expressions [21, 22]. Duration of toxicity effects following acute methadone poisoning is unpredictable. Because of the long duration of action of methadone, if oversedation or respiratory depression occurs, a prolonged period of observation may be needed; and if naloxone is required, it may need to be repeated or given as an infusion for many hours $[23,24]$. There were a small number of cases where patients had relapse signs and symptoms of toxicity upon discontinuation of naloxone infusion [18]. It was suggested in that study for continuous monitoring of patients for at least $72 \mathrm{~h}$ [14].
As noted in this case, post $48 \mathrm{~h}$ of naloxone infusion while tapering patient dose down, patient started to have bradycardia. Dosage of patient was increased and infused for another $30 \mathrm{~h}$. Naloxone was known to be the effective and safe antidote for opioid poisoning when given as intermittent boluses or continuous infusion to opioid-naive patients $[25,26]$.

"Take-home dose" practice was generally not encouraged in the current MMT programme. It was feared that "take-home dose" of methadone may be misused (i.e., injected intravenously, used as cocktail, etc.) by intravenous drug users. Inadequate patient education on its toxicity effect, safe handling and storage of methadone bottle may lead to accidental ingestion by children, which is proven to be potentially fatal [4]. In government MMT clinics, participants of MMT programme will only be allowed to take home 3-day doses of methadone syrup (i.e., one dose of diluted methadone syrup per bottle) after evaluation and approval by authorized officers of their MMT clinic. Only patients who are consistently following DOT in methadone clinic and actively involved in counseling sessions over a defined period, well-behaved and adhered well to rules and regulations, having a proper and productive career/job of which daily DOT may affect his job, and not involved in sales or used of illicit drugs, may be suitable candidates for "takehome dose". In that case, this group of methadone patients need to be constantly reminded and counseled on safe keeping of methadone bottles at home and away from reach of children $[4,7,27]$. Furthermore, we hope that a new MMT policy can be enacted to replace all the "take-home dose" methadone bottle with bottle with child-resistant cap [27].

\section{Conclusions}

This case reminded us that methadone poisoning in children can potentially be life-threatening if early signs and symptoms of poisoning are not identified and eventually missed. Trial with one to two bolus doses of IV naloxone may be helpful in supporting the diagnosis of methadone poisoning in settings without methadone serum/plasma concentration assay services. Prolonged course of continuous infusion of IV naloxone is effective in reversing the signs and symptoms of methadone toxicity in children.

\section{Acknowledgments}

We would like to thank the Director General of Health Malaysia for his permission to publish this article.

\section{Financial Disclosure}

No funding was secured for this case report.

\section{Conflict of Interest}

The authors declare that they have no conflicts of interest. 


\section{Informed Consent}

Written consent was obtained from patient's caregiver (father).

\section{Author Contributions}

Tang Kai Lun and Balamurugan Supparamaniam drafted the initial case report, reviewed and revised the manuscript. Balamurugan Supparamaniam registered the case report on National Medical Research Registry (NMRR) and obtained approval for publication of case from Director General of Health, Ministry of Health Malaysia. Dr. Rahmah Yunus and Fong Jing Ying counter-checked and critically reviewed all clinical and laboratory data and prepared the discussions. All authors approved the final manuscript as submitted and agree to be accountable for all aspects of the work.

\section{Data Availability}

The authors declare that data supporting the findings of this study are available within the article.

\section{Abbreviations}

MMT: methadone maintenance therapy; IVDU: intravenous drug user; CIVI: continuous intravenous infusion; HIV: human immunodeficiency virus; $\mathrm{FMO}_{2}$ : facemask oxygen; GP: general practitioner; CRT: capillary refill time; NAI: non-accidental injury; DOT: direct-observed-therapy; GCS: Glasgow coma scale; BP: blood pressure; PR: pulse rate; RR: respiratory rate; $\mathrm{SPO}_{2}$ : pulse oximetry

\section{References}

1. Brown R, Kraus C, Fleming M, Reddy S. Methadone: applied pharmacology and use as adjunctive treatment in chronic pain. Postgrad Med J. 2004;80(949):654-659.

2. Abdul Aziz S, et al. Malaysian methadone treatment outcome study (MyTOS) 2016. Ministry of Health. 2016.

3. Babar ZUD, Zaini N, Yee C. Harm reduction program and methadone poisoning: implications for pediatric public health in Malaysia. Journal of Pharmacy Practice. 2006;19:280-281.

4. Li L, Levine B, Smialek JE. Fatal methadone poisoning in children: Maryland 1992-1996. Subst Use Misuse. 2000;35(9):1141-1148.

5. Garis Panduan Pendispensan Rawatan Terapi Gantian Metadon. Bahagian Perkhidmatan Farmasi, MOH (Malaysia). 2017. [In English: Dispensing Guideline for Methadone Replacement Therapy, Pharmaceutical Services Division, Ministry of Health, Malaysia].

6. Ghorbani F, et al. Methadone poisoning in children and some factors affecting it: A cross-sectional study in Tabriz, Northwest of Iran. International Journal of Pediat- rics. 2015;3:725-731.

7. Allameh Y, et al. Methadone poisoning in children: a systematic review and meta-analysis in Iran. Journal of Pediatrics Review. 2017;5(2):1-8.

8. Alotaibi N, Sammons H, Choonara I. Methadone toxicity in children. Archives of Disease in Childhood. 2012;97(5):e1-e1.

9. Chou R, Cruciani RA, Fiellin DA, Compton P, Farrar JT, Haigney MC, Inturrisi C, et al. Methadone safety: a clinical practice guideline from the American Pain Society and College on Problems of Drug Dependence, in collaboration with the Heart Rhythm Society. J Pain. 2014;15(4):321-337.

10. Ward RM, Drover DR, Hammer GB, Stemland CJ, Kern S, Tristani-Firouzi M, Lugo RA, et al. The pharmacokinetics of methadone and its metabolites in neonates, infants, and children. Paediatr Anaesth. 2014;24(6):591-601.

11. Mott C, Sarpal A, Moss K, Herbert A. Methadone for analgesia in children with life-limiting illness: experience from a Tertiary Children's Health Service. Children (Basel). 2018;5(7):86.

12. Berde CB, Beyer JE, Bournaki MC, Levin CR, Sethna NF. Comparison of morphine and methadone for prevention of postoperative pain in 3- to 7-year-old children. $\mathrm{J}$ Pediatr. 1991;119(1 Pt 1):136-141.

13. Sachdeva DK, Stadnyk JM. Are one or two dangerous? Opioid exposure in toddlers. J Emerg Med. 2005;29(1):77-84.

14. Sharif MR, Nouri S. Clinical Signs and Symptoms and Laboratory Findings of Methadone Poisoning in Children. Iran J Pediatr. 2015;25(1):e176.

15. Jabbehdari S, Farnaghi F, Shariatmadari SF, Jafari N, Mehregan FF, Karimzadeh P. Accidental children poisoning with methadone: an Iranian pediatric sectional study. Iran J Child Neurol. 2013;7(4):32-34.

16. Ghaemi N, et al. A Cross sectional study of opioid poisoning in children at a tertiary center. Asia Pacific Journal of Medical Toxicology. 2016;5(4):115-118.

17. Storey $\mathrm{P}$, et al. Hospice and palliative care training for physicians: a self-study program. Glenview, IL: American Academy of Hospice and Palliative Medicine. 2008.

18. Fariba Farnaghi, Narjes Jafari, Fatemeh-Fereshteh Mehregan. Methadone poisoning among children referred to Loghman-Hakim Hospital in 2009. Pajoohande. 2012;16(6):299-303.

19. Eizadi-Mood N, Yaraghi A, Sharifian Z, Feizi A, Hedaiaty M, Sabzghabaee AM. Clinical presentation and the outcome of therapy in a cohort of patients with methadone toxicity in Iran. Mater Sociomed. 2015;27(4):276-279.

20. McCurley WS, Tunnessen WW, Jr. Methadone toxicity in a child. Pediatrics. 1969;43(1):90-92.

21. Berde CB, et al. Pharmacokinetics of methadone in children and adolescents in the perioperative period. Anesthesiology: The Journal of the American Society of Anesthesiologists. 1987;67(3):A519-A519.

22. Eap CB, Buclin T, Baumann P. Interindividual variability of the clinical pharmacokinetics of methadone: implications for the treatment of opioid dependence. Clin Pharmacokinet. 2002;41(14):1153-1193. 
23. Waldron VD, Klimt CR, Seibel JE. Methadone overdose treated with naloxone infusion. JAMA. 1973;225(1):53.

24. Rzasa Lynn R, Galinkin JL. Naloxone dosage for opioid reversal: current evidence and clinical implications. Ther Adv Drug Saf. 2018;9(1):63-88.

25. Clark AK, Wilder CM, Winstanley EL. A systematic review of community opioid overdose prevention and nalox- one distribution programs. J Addict Med. 2014;8(3):153163.

26. Boyer EW. Management of opioid analgesic overdose. N Engl J Med. 2012;367(2):146-155.

27. Bloor RN, McAuley R, Smalldridge N. Safe storage of methadone in the home-an audit of the effectiveness of safety information giving. Harm Reduct J. 2005;2:9. 